\title{
Qualidade sanitária e fisiológica de sementes de sorgo tratadas com extratos aquosos e óleos essenciais
}

\section{Health and physiological quality of sorghum seeds treated with aqueous extracts and essential oils}

\author{
Nicoletta Stefânia Dias da Silva Flávio ${ }^{1 *}$; Nilza de Lima Pereira Sales²; \\ César Fernandes Aquino ${ }^{3}$; Eriksen Patric Souza Soares ${ }^{4}$; \\ Lucas Franklin Souza Aquino ; Hugo César Rodrigues Moreira Catão ${ }^{6}$
}

\section{Resumo}

Objetivou-se com o presente estudo avaliar a eficiência de extratos aquosos e óleos essenciais na qualidade sanitária e fisiológica de sementes de sorgo da cultivar BR 310. Foram realizados dois experimentos, um utilizando sementes de sorgo tratadas com extratos aquosos de Cinnamomum zeylanicum e Mentha spicata e outro, utilizando óleos essenciais de Ocimum gratissimum e Annona crassiflora. Para o experimento com extratos as concentrações foram $0,10,20$ e $30 \%$ e para os óleos foram $0,5,10$ e 15 $\mu \mathrm{L} / \mathrm{mL}$. Foram avaliadas as seguintes características: sanidade de sementes (Blotter test), germinação, primeira contagem de germinação e índice de velocidade de germinação. O delineamento utilizado foi o DIC em esquema fatorial 2 x 4, sendo dois extratos ou dois óleos e quatro concentrações, em ensaios independentes. Várias espécies fúngicas estavam associadas às sementes, sendo o gênero Curvularia a de maior incidência. O extrato aquoso de canela (Cinnamomum zeylanicum) e o óleo essencial de alfavaca cravo (Ocimum gratissimum) reduzem a infestação dos fungos, principalmente de Curvularia, porém apresentam efeito fitotóxico reduzindo a viabilidade e o vigor das sementes de sorgo.

Palavras-chave: Sorghum bicolor, Cinnamomum zeylanicum, Ocimum gratissimum, controle alternativo, germinação, patologia de sementes

\footnotetext{
Abstract

The objective of the present study was to evaluate the efficiency of aqueous extracts and essential oils on seed quality of sorghum cultivar BR 310. Two experiments were conducted, one using sorghum seeds treated with aqueous extract of Cinnamomum zeylanicum and Mentha spicata and another using essential oils of Ocimum gratissimum and Annona crassiflora. For the experiment with extracts concentrations were $0,10,20$ and $30 \%$ and for the oils were $0,5,10$ and $15 \mu \mathrm{L} / \mathrm{mL}$. We evaluated the following characteristics: seed health (Blotter test), germination, first count of germination and germination speed index. The design was a DIC in 2 x 4 factorial arrangement, two oils or two extracts

${ }^{1}$ Eng $^{\circ}$ Agr $^{\circ}$, M.e em Ciências Agrárias, Universidade Federal de Minas Gerais, Instituto de Ciências Agrárias, UFMG/ICA, Montes Claros, MG. E-mail: nicole_stefany@yahoo.com.br

${ }^{2}$ Eng $^{\mathrm{a}}$ Florestal, Prof ${ }^{\mathrm{a}} \mathrm{Dr}^{\mathrm{a}}$ em Fitopatologia, Montes Claros, MG. E-mail: nsales@ufmg.br

${ }^{3}$ Eng $^{\mathbf{o}}$ Agr $^{\circ}$, Discente de Doutorado em Fitotecnia, Univrsidade Federal de Viçosa, UFV, Viçosa, MG. E-mail: cesarfernandesaquino@ yahoo.com.br

${ }^{4}$ Eng $^{\text {O Agr }}{ }^{\circ}$, Discente de Mestrado em Produção Vegetal, Universidade Estadual de Montes Claros, UNIMONTES, Janaúba, MG. E-mail: eriksenpatric@yahoo.com.br

${ }^{5}$ Eng $^{\mathrm{o}} \mathrm{Agr}^{\mathrm{o}}$, Universidade Federal de Minas Gerais, Instituto de Ciências Agrárias, UFMG/ICA, Montes Claros, MG. E-mail: voxfranklin@yahoo.com.br

${ }^{6}$ Eng $^{\circ}$ Agr ${ }^{\circ}$, Dr. em Fitotecnia, Universidade Federal de Lavras, UFLA, Lavras, MG. E-mail: hugocatao@yahoo.com.br

* Autor para correspondência
} 
with four concentrations, independent testing. Several fungal species were associated with the seed, and the genus Curvularia the most prevalent. The aqueous extract of cinnamon (Cinnamomum zeylanicum) and clove essential oil of basil (Ocimum gratissimum) have shown promise for the treatment of seeds, reducing fungal infestation, especially Curvularia, however have phytotoxic effect reducing the viability and vigor of sorghum seeds.

Key words: Sorghum bicolor, Cinnamomum zeylanicum, Ocimum gratissimum, alternative control, germination and seed pathology

\section{Introdução}

O Sorgo (Sorghum bicolor L. Moench) é o quinto cereal mais importante no mundo (FAO, 2012), sendo utilizado como matéria-prima na produção de álcool anidro, farinhas, bebidas alcoólicas, tintas e vassouras (RIBAS, 2003). Pode-se destacar como fatores limitantes da sua produtividade a dificuldade de se obter sementes com qualidade física, fisiológica, genética e sanitária, devido à morfologia da inflorescência e disposição das sementes (CARVALHO et al., 2000).

Asementeé o meio mais eficiente de disseminação de patógenos, propiciando, dentre outras coisas a introdução de doenças em novas áreas, reduzindo a produção de determinadas culturas. Os principais danos que os microorganismos causam são a morte de plântulas pré e pós-emergência, podridões radiculares, infecção da parte aérea com reflexos sobre a qualidade das sementes, o que pode gerar perda de vigor, germinação e apodrecimento. Entretanto, os fungos de armazenamento, como por exemplo, do gênero Aspergillus, além destes danos às sementes, ainda produzem micotoxinas que podem causar intoxicações alimentares (PINTO, 2001). O inóculo presente na semente também pode resultar em aumento progressivo de uma dada doença no campo, podendo com isso reduzir o valor comercial da cultura. Os testes de qualidade fisiológica em sementes podem esclarecer as causas de uma baixa germinação, o que é comum em amostras com elevados índices de infecção (HENNING, 2005).

No manejo integrado de doenças de plantas o tratamento de sementes constitui uma medida valiosa pela sua simplicidade de execução, baixo custo relativo e eficácia sob vários aspectos (MACHADO, 2000). Pelo fato dos custos com produtos químicos serem elevados para a realização destes tratamentos, e com o aumento do consumo de produtos orgânicos e a busca por uma agricultura menos poluidora, tem-se estudado a utilização de produtos alternativos para tratamento de sementes. Pesquisas envolvendo sanidade e germinação de sementes de milho, feijão e soja tratadas com óleos essenciais de Eremanthus erythropappus, Cymbopogon martinii e Rosmarinus officinalis foram realizadas por Hillen et al. (2012), verificando que os óleos influenciaram diferentemente nos parâmetros analisados. Cymbopogon martinii (20 $\mu \mathrm{L})$, Eremanthus erythropappus e Rosmarinus officinalis $(200 \mu \mathrm{L})$ quando adicionados ao meio de cultivo inibiram o desenvolvimento dos patógenos em $100 \%$, além disso, proporcionaram os menores percentuais de sementes assintomáticas germinadas.

A utilização de óleos essenciais na concentração de 2,0 $\mathrm{mg} \mathrm{mL}^{-1}$, também foi estudada por Viegas et al. (2005), sendo verificado que o óleo de bulbilhos de alho e de casca de canela inibiram o crescimento micelial de Aspergillus flavus. Resultados satisfatórios também foram observados por Sousa, Serra e Melo (2012) testando o efeito de óleos essenciais (copaíba, andiroba, babaçu, coco, neem, eucalipto, uva, amêndoa, hortelã, pau rosa) no controle de C. gloeosporidoides em pimenta, no entanto, os óleos de babaçu, semente de uva e amêndoa não inibiram in vitro o crescimento do fungo. Entretanto, quando testados os óleos na póscolheita da pimenta foi observado que apenas o óleo essencial de babaçu não foi eficiente em reduzir a lesão da antracnose, isso indica que alguns óleos, como o de semente de uva e amêndoa, possam funcionar como indutores de resistência.

Além dos óleos essenciais, outros princípios 
ativos derivados de metabólitos secundários presentes em extratos de plantas medicinais também são usados com intuito de inibir o desenvolvimento de organismos fitopatogênicos. O extrato de folhas de Plectranthus barbatus reduziu o crescimento micelial de Colletotrichum musae, C. gloeosporiodes (isolado de mamão), C. gloeosporiodes (isolado de cacau) e C. lindemuthianum em 82, 49, 47 e 53\%, respectivamente (SILVA et al., 2008).

A utilização de extratos e óleos essenciais de plantas medicinais com propriedades antimicrobianas destaca-se como alternativa para substituir a aplicação de produtos químicos. Por isso, estes compostos são frequentemente empregados com sucesso no controle de fungos fitopatogênicos. Essa alternativa pode ser agregada às demais práticas de manejo integrado de doenças e contribuir para atender à crescente demanda internacional e nacional por produtos orgânicos (SANTOS; CARVALHO; LACERDA, 2008). É de fundamental importância que os tratamentos de sementes controlem, ou diminuam a infecção por patógenos, mas não causem danos à qualidade fisiológica das sementes. Desta forma, objetivou-se com o presente estudo avaliar o efeito de extratos aquosos e óleos essenciais de plantas na qualidade sanitária e fisiológica de sementes de sorgo.

\section{Material e Métodos}

Os experimentos foram conduzidos nos Laboratórios de Fitopatologia e de Análises de Sementes do Instituto de Ciências Agrárias (ICA) da Universidade Federal de Minas Gerais, em Montes Claros. Foram utilizadas nos experimentos sementes de sorgo da cultivar BR 310 adquirida no comércio local.

\section{Obtenção dos extratos e óleos essenciais}

Os extratos vegetais utilizados foram obtidos a partir de folhas frescas de hortelã (Mentha spicata) colhidas no Horto Medicinal do ICA e canela (Cinnamomum zeylanicum) em casca adquirida no Mercado Municipal da cidade. Os óleos foram preparados a partir de sementes de araticum (Annona crassiflora) e de folhas frescas de alfavaca cravo (Ocimum gratissimum L.). Todo o material vegetal após a coleta foi lavado em água corrente e desinfetado em hipoclorito de sódio, a $0,5 \%$, durante trinta minutos, a fim de eliminar microrganismos presentes na superfície do mesmo. Decorrido este período, os materiais foram lavados com tríplice lavagem em água corrente, para retirar o excesso de hipoclorito, e secos em papel toalha durante 24 horas. Em seguida, os materiais foram acondicionados em sacos de papel e colocados em estufa, com circulação forçada de ar a $45^{\circ} \mathrm{C}$, por 96 horas para folhas e 120 horas para cascas e sementes. Após a secagem, o material foi moído em moinho de faca (GARCIA et al., 2012).

Os extratos de hortelã e canela foram obtidos pela adição de 50 gramas de cada espécie vegetal, trituradas por 2 minutos em liquidificador contendo $500 \mathrm{~mL}$ de água destilada esterilizada para extração dos princípios ativos. Após a trituração, cada extrato foi filtrado em papel de filtro esterilizado e mantido em recipiente limpo e estéril para o tratamento das sementes seguindo a metodologia proposta por Coelho et al. (2011).

Para a obtenção do óleo essencial de araticum foram usados 50 gramas do material seco e moído por extração contínua a quente $\left(70^{\circ} \mathrm{C}\right)$ e como solvente utilizou-se $100 \mathrm{~mL}$ de éter de petróleo 40$60^{\circ} \mathrm{C}$ em extrator tipo Soxhlet. Após a recuperação automática do solvente no próprio extrator, o resíduo foi levado para uma estufa por 30 minutos a $100^{\circ} \mathrm{C}$, para a evaporação total do solvente residual. O teor de óleo foi determinado por pesagem do resíduo totalmente seco (CECCHI, 2003). Após, o óleo foi coletado e acondicionado em vidro âmbar. O óleo essencial de alfavaca cravo foi extraído por hidrodestilação em extrator do tipo Clevenger modificado e para isso 50 gramas de material foram colocadas em balão de vidro e seu volume completado com água deionizada até atingir $2 / 3$. O 
processo de extração foi conduzido durante 3 horas, sendo que, ao final, o óleo foi separado da água por separação líquido-líquido (PRINS; LEMOS; FREITAS, 2006).

\section{Sanidade de sementes de sorgo}

Um teste de sanidade controle foi realizado para verificar os principais fungos que infestavam as sementes de sorgo. Por meio do método "Blotter test" com congelamento, sementes foram dispostas em caixas gerbox, sobre duas folhas de papel mata borrão umedecido com meio ágar-água a 10\% (MACHADO, 2000). Em seguida foram acondicionadas em incubadora por 24 horas, com fotoperíodo de 12 horas e temperatura de $20 \pm 2^{\circ} \mathrm{C}$. Após esse período as caixas foram colocadas em congelamento por 24 horas a temperatura de $-20^{\circ} \mathrm{C}$ sendo novamente acondicionadas nas mesmas condições iniciais de incubação (BRASIL, 2009). Após sete dias de incubação, avaliou-se o número de sementes infestadas por diferentes gêneros de fungos filamentosos que se desenvolveram, os quais foram identificados a partir de observações macroscópicas e microscópicas de suas características e estruturas seguindo a chave de identificação proposta por Pitt e Hocking (1985).

Posteriormente sementes do mesmo lote foram imersas por 15 minutos nos extratos ou nos óleos essenciais diluídos para serem tratadas com as respectivas concentrações testadas, sendo em seguida colocadas em papel de filtro esterilizado para secar durante 30 minutos (VIEGAS et al., 2005). As concentrações utilizadas para os extratos foram $0,10,20$ e $30 \%(10,20$ e $30 \mathrm{~mL}$ do extrato bruto para $100 \mathrm{~mL}$ de água destilada estéril, respectivamente). Para os óleos essenciais, as concentrações utilizadas foram menores, devido à maior concentração de princípio ativo sendo utilizadas as seguintes concentrações: 0, 5, 10 e 15 $\mu \mathrm{L} / \mathrm{mL}$. Para facilitar a emulsificação dos óleos em água, empregou-se o Tween 80 a 1\% (v/v) (BRITO et al., 2010). O tratamento 0 (zero) correspondeu à água destilada estéril pura. As sementes foram incubadas nas mesmas condições descritas anteriormente e realizou-se o teste de sanidade a fim de verificar o efeito do tratamento no controle dos diferentes fungos encontrados.

O fungo que apresentou a maior incidência (Curvularia) foi isolado em cultura pura a partir de sementes de sorgo contaminadas. A sua multiplicação foi realizada por transferências de fragmentos de micélio para placas de Petri, de $9 \mathrm{~cm}$ de diâmetro, contendo meio BDA (BatataDextrose-Ágar), incubadas por 10 dias a $25^{\circ} \mathrm{C}$ e fotoperíodo de 12 horas de luz. Após completo desenvolvimento das colônias, sementes foram depositadas em camada única sobre as culturas crescidas em placas, retornando para a câmara de crescimento onde permaneceu por mais 48 horas. As sementes inoculadas com Curvularia foram tratadas com as mesmas concentrações dos extratos e óleos essenciais e posteriormente foi montado teste de sanidade para verificar controle deste fungo nas sementes.

Utilizou-se o delineamento inteiramente casualizado (DIC), em esquema fatorial 2 x 4, sendo dois extratos ou dois óleos e quatro concentrações. Para cada tratamento foram utilizadas 200 sementes, divididas em 8 repetições de 25 sementes.

\section{Qualidade fisiológica de sementes de sorgo}

Foram utilizadas as mesmas concentrações do teste de sanidade, ou seja, $0,10,20$ e $30 \%$ para os extratos e $0,5,10$ e $15 \mu \mathrm{L} / \mathrm{mL}$ para os óleos e, as sementes, previamente desinfestadas, foram submetidas aos tratamentos da mesma forma que no experimento anterior. As sementes assim tratadas foram distribuídas em rolos papel germitest umedecidos com água destilada, em quantidade equivalente a 2,5 vezes o peso do papel e colocadas em germinador por 10 dias com temperatura de 25 ${ }^{\circ} \mathrm{C}$, realizado conforme recomendações das Regras para Análises de Sementes-RAS (BRASIL, 2009). As sementes foram consideradas germinadas pela 
ocorrência da protrusão da radícula em $5 \mathrm{~mm}$. Aos 4 e 10 dias após a semeadura foi avaliado o número de plântulas normais para primeira contagem e percentagem de germinação, respectivamente. Foram realizadas contagens diárias de emissão de radícula, para avaliação do índice de velocidade de germinação (IVG). Para o cálculo do IVG utilizouse a fórmula sugerida por Maguire (1962).

O delineamento utilizado foi o DIC em esquema fatorial $2 \times 4$, sendo dois extratos ou dois óleos e quatro concentrações com 4 repetições de 50 sementes.

\section{Análise dos dados}

Os dados foram submetidos à análise de variância e as médias comparadas pelo teste de Tukey a $(\mathrm{P}<0,05)$ de probabilidade. Os dados de percentagem foram transformados para $y=\operatorname{arcsen}(\sqrt{x / 100})$.

\section{Resultados e Discussão}

Sanidade de sementes de sorgo

Os fungos infestantes das sementes de sorgo encontrados no teste de sanidade controle estão relacionados na Tabela 1, onde se observa que os gêneros Penicillium (12,8\%), Curvularia (43\%), Fusarium (29,2\%) e Aspergillus (14,3\%) foram os mais frequentes. Martins Netto et al. (1998) também relataram que os principais fungos ocorrentes em sementes de sorgo são Penicillium, Aspergillus, Rhizopus, Alternaria, Curvularia, Fusarium. Considerados fungos de armazenamento, Aspergillus spp. e Penicillium spp., além de deteriorarem grãos e sementes, são produtores de micotoxinas que são altamente tóxicos para os seres humanos, animais e plantas (REVERBERI et al., 2010). Fusarium spp. também pode produzir micotoxinas, além disso pode causar redução da capacidade germinativa, descoloração ou formação de manchas, apodrecimentos, mofos e transformações bioquímicas nas sementes (SOUZA; ARAÚJO; NASCIMENTO, 2007).

Tabela 1. Principais gêneros de fungos infestantes e sua incidência (\%) em sementes de sorgo no "Blotter test" controle.

\begin{tabular}{lc}
\hline Fungos & $\mathbf{( \% )}$ \\
\hline Penicillium & 12,8 \\
Aspergillus & 14,3 \\
Trichoderma & 4,2 \\
Curvularia & 43,0 \\
Rhizopus & 3,0 \\
Colletotrichum & 0,3 \\
Fusarium & 29,2 \\
Drescheslera & 7,8 \\
Alternaria & 1,9 \\
Chaetomium & 0,1 \\
\hline Total & 89,3 \\
\hline
\end{tabular}

Fonte: Elaboração dos autores. 
Houve efeito da interação entre os extratos e as concentrações testadas, o extrato de canela foi eficiente em reduzir a infestação de fungos em todas as concentrações testadas quando comparado ao extrato de hortelã (Tabela 2). Venturoso et al. (2011) verificaram que o extrato de hortelã apresentou atividade antifúngica intermediária sobre o desenvolvimento de fitopatógenos. Diferentemente de Piveta et al. (2007) que constataram que o extrato de hortelã controlou fungos como Penicillium.

Tabela 2. Efeito de extratos aquosos de Cinnamomum zeylanicum e Mentha spicata sobre a incidência de todos os fungos infestantes das sementes de sorgo.

\begin{tabular}{ccc}
\hline Concentração (\%) & Cinnamomum zeylanicum & Mentha spicata \\
\hline 0 & $76,5 \mathrm{a}$ & $85,0 \mathrm{a}$ \\
10 & $19,5 \mathrm{~b}$ & $73,5 \mathrm{a}$ \\
20 & $16,5 \mathrm{~b}$ & $78,0 \mathrm{a}$ \\
30 & $15,5 \mathrm{~b}$ & $82,0 \mathrm{a}$ \\
\hline $\mathrm{CV}(\%)$ & 5,91 & 4,77 \\
\hline
\end{tabular}

Médias seguidas pela mesma letra minúscula na linha, não diferem entre si pelo teste de Tukey a 5\% de probabilidade.

Fonte: Elaboração dos autores.

De toda microflora fúngica verificada pelo teste de sanidade o extrato de canela reduziu $61 \%$ quando se comparou à concentração de $0 \%$ com a de $30 \%$ (Tabela 2). Ocorreu redução linear da infestação na medida em que aumentou a concentração do extrato de canela (Figura 1). Viegas et al. (2005) verificaram que o óleo essencial de canela possui propriedades antifúngicas sobre o desenvolvimento de A. flavus. As propriedades antifúngicas mencionadas são o eugenol e o cinamaldeído, sendo este último o principal composto que possui atividade no controle de microrganismos (JHAM et al., 2005). O eugenol também já foi indicado como responsável por inibir o crescimento de patógenos (VIEIRA; SIMON, 2000). Neste trabalho pôde ser comprovado que estas propriedades também estão presentes no extrato aquoso, corroborando com os resultados obtidos por Venturoso et al. (2011) que constataram que o extrato de canela proporcionou fungitoxidade sobre Cercospora kikuchii, Colletotrichum sp., Penicillium sp., e Phomopsis sp.

Figura 1. Porcentagem de sementes de sorgo infestadas com fungos tratadas com extratos vegetais de C. zeylanicum e M. spicata.

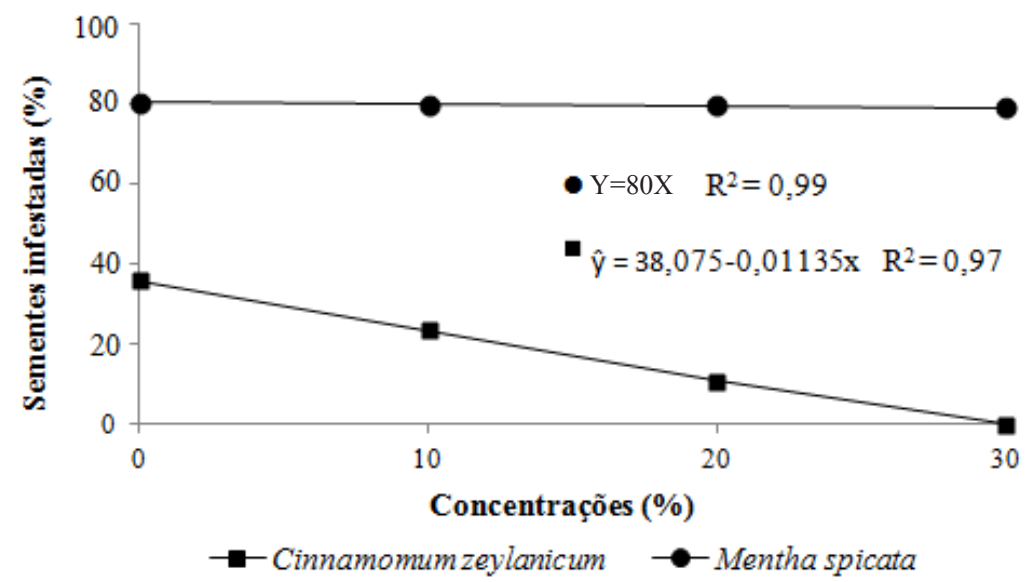

Fonte: Elaboração dos autores. 
O fungo do gênero Curvularia foi o mais incidente nas sementes de sorgo e houve interação dos extratos versus concentrações testadas (Tabela 3). Sementes de feijão caupi também apresentaram grande diversidade fúngica e dentre os gêneros encontrados, Curvularia possuía alta incidência (SILVA et al., 2009). No entanto, Pinto (2004) relatou baixa incidência $(2,5 \%)$ de Curvularia lunata em sementes de sorgo, contudo perdas tanto qualitativas quanto quantitativas ficaram evidenciadas havendo redução no tamanho e no peso das sementes inoculadas artificialmente com C. lunata. Com isso, o tratamento das sementes com o extrato de canela reduziu a incidência dos fungos, principalmente de Curvularia, mostrando-se eficaz em todas as concentrações testadas em relação ao extrato de hortelã (Tabela 3 ). Ao contrário do extrato de canela que reduziu linearmente a infestação de Curvularia, não foi verificado redução sobre a incidência quando se utilizou o extrato de hortelã nas sementes. Contudo foi verificado incremento do fungo em função do aumento das doses do extrato de hortelã (Figura 2). Talvez, este crescimento do patógeno tenha sido devido em decorrência de algum componente nutricional da hortelã. Araújo et al. (2009) relata que algum componente nutricional contido no extrato aquoso de alho promoveu o crescimento de Penicillium roqueforti com o aumento da concentração do extrato. Resultados pouco satisfatórios no controle de patógenos também foram relatados por Silva et al. (2012) utilizando extrato de hortelã no crescimento in vitro de C. gloeosporioides, F. oxysporum f. sp. vasinfectum e P. oryzae.

Tabela 3. Efeito de extratos aquosos de Cinnamomum zeylanicum e Mentha spicata sobre a incidência de Curvularia em sementes de sorgo.

\begin{tabular}{ccc}
\hline Concentração (\%) & Cinnamomum zeylanicum & Mentha spicata \\
\hline 0 & $47,2 \mathrm{a}$ & $37,4 \mathrm{a}$ \\
10 & $21,1 \mathrm{~b}$ & $46,2 \mathrm{a}$ \\
20 & $0 \mathrm{~b}$ & $55,5 \mathrm{a}$ \\
30 & $0 \mathrm{~b}$ & $53,6 \mathrm{a}$ \\
\hline CV $(\%)$ & 7,10 & 5,48 \\
\hline
\end{tabular}

Médias seguidas pela mesma letra minúscula na linha, não diferem entre si pelo teste de Tukey a 5\% de probabilidade.

Fonte: Elaboração dos autores.

Figura 2. Infestação por Curvularia em sementes de sorgo tratadas com extratos vegetais de C. zeylanicum e $M$. spicata.



Fonte: Elaboração dos autores. 
Houve interação entre os óleos essenciais e as suas concentrações, sendo o tratamento com o óleo de alfavaca cravo o mais eficiente em todas as suas dosagens, reduzindo o número de sementes infestadas quando comparada ao óleo de araticum (Tabela 4 e Figura 3). À medida que aumentou a concentração do óleo de alfavaca cravo, observouse redução na incidência fúngica, no entanto, quando as sementes foram tratadas com o óleo de araticum esta redução foi menor. Estes resultados são contraditórios aos observados por Silva et al. (2012), que utilizaram extrato aquoso Ocimum basilicum e não obtiveram sucesso no controle micelial in vitro dos patógenos. Em contrapartida, Souza Junior et al. (2009) relataram a inibição de 100\% de conídios de C. gloeosporioides utilizando óleo essencial de alfavaca cravo. Este óleo possui, segundo a literatura consultada, propriedades antifúngica, antibacteriana, antidiarréica, hipoglicemiante e anti-inflamatória (RABELO et al., 2003). Segundo Vieira e Simon (2000), o eugenol é componente majoritário do óleo essencial de $O$. gratissimum.

Tabela 4. Efeito de óleos essenciais de Ocimum gratissimum e Annona crassiflora sobre a incidência de todos os fungos infestantes das sementes de sorgo.

\begin{tabular}{ccc}
\hline Concentração $(\boldsymbol{\mu l} / \mathbf{m L})$ & Ocimum gratissimum & Annona crassiflora \\
\hline 0 & $95,5 \mathrm{a}$ & $100 \mathrm{a}$ \\
5 & $79,5 \mathrm{~b}$ & $95,5 \mathrm{a}$ \\
10 & $63,0 \mathrm{~b}$ & $94,0 \mathrm{a}$ \\
15 & $62,5 \mathrm{~b}$ & $92,0 \mathrm{a}$ \\
\hline $\mathrm{CV}(\%)$ & 6,85 & 4,93 \\
\hline
\end{tabular}

Médias seguidas pela mesma letra minúscula na linha, não diferem entre si pelo teste de Tukey a 5\% de probabilidade.

Fonte: Elaboração dos autores.

Figura 3. Porcentagem de sementes de sorgo infestadas com fungos tratadas com extratos vegetais de $O$. gratissimum e A. crassiflora.

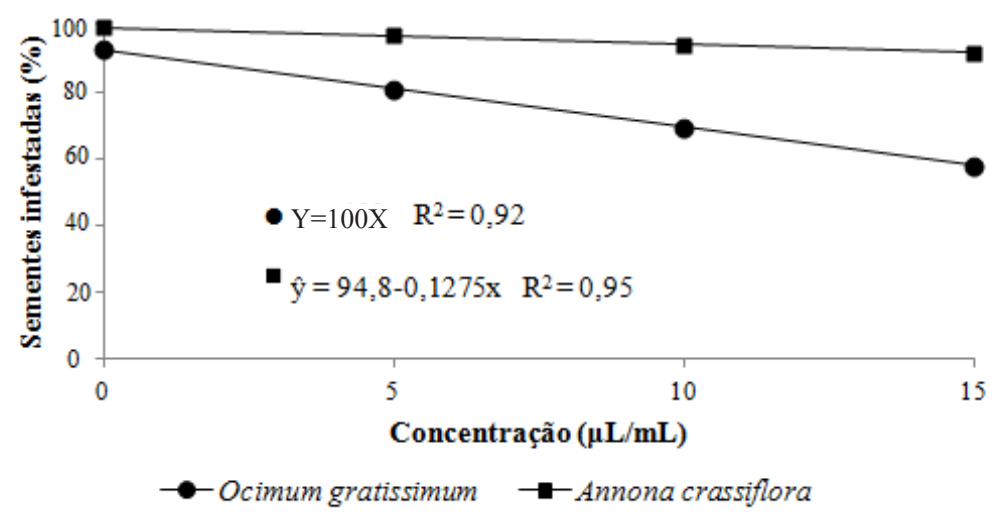

Fonte: Elaboração dos autores.

Ocorreu interação entre a incidência de concentrações do óleo de araticum não houve Curvularia nas sementes tratadas com óleo efeito no controle da infestação dos fungos (Tabela essencial de alfavaca cravo e a maior concentração testada. Houve redução linear com o aumento da concentração sendo a dosagem de $15 \mu \mathrm{L} / \mathrm{mL}$ a mais eficiente no controle do patógeno. Já nas 5 e Figura 4). O uso de extratos vegetais e óleos essenciais são potentes biofungicidas naturais devido aos resultados alcançados, esses se têm mostrado promissores para a utilização prática no 
controle de diversos fitopatógenos. Para Siqui et al. (2000) os óleos essenciais estão relacionados com inúmeras funções necessárias a sobrevivência vegetal, tendo um importante papel na defesa contra microrganismos e tem sido estabelecido cientificamente que cerca de $60 \%$ dos óleos possuem propriedades antifúngicas.

Tabela 5. Efeito de óleos essenciais de Ocimum gratissimum e Annona crassiflora sobre a incidência de Curvularia em sementes de sorgo.

\begin{tabular}{ccc}
\hline Concentração $(\boldsymbol{\mu l} / \mathbf{m L})$ & Ocimum gratissimum & Annona crassiflora \\
\hline 0 & $47,6 \mathrm{a}$ & $39,5 \mathrm{a}$ \\
5 & $51,8 \mathrm{a}$ & $50,5 \mathrm{a}$ \\
10 & $42,6 \mathrm{a}$ & $42,0 \mathrm{a}$ \\
15 & $21,8 \mathrm{~b}$ & $39,7 \mathrm{a}$ \\
\hline $\mathrm{CV}(\%)$ & 8,61 & 9,37 \\
\hline
\end{tabular}

Médias seguidas pela mesma letra minúscula na linha, não diferem entre si pelo teste de Tukey a 5\% de probabilidade. Fonte: Elaboração dos autores.

Figura 4. Infestação por Curvularia em sementes de sorgo tratadas com óleos essenciais de O. gratissimum e A. crassiflora.

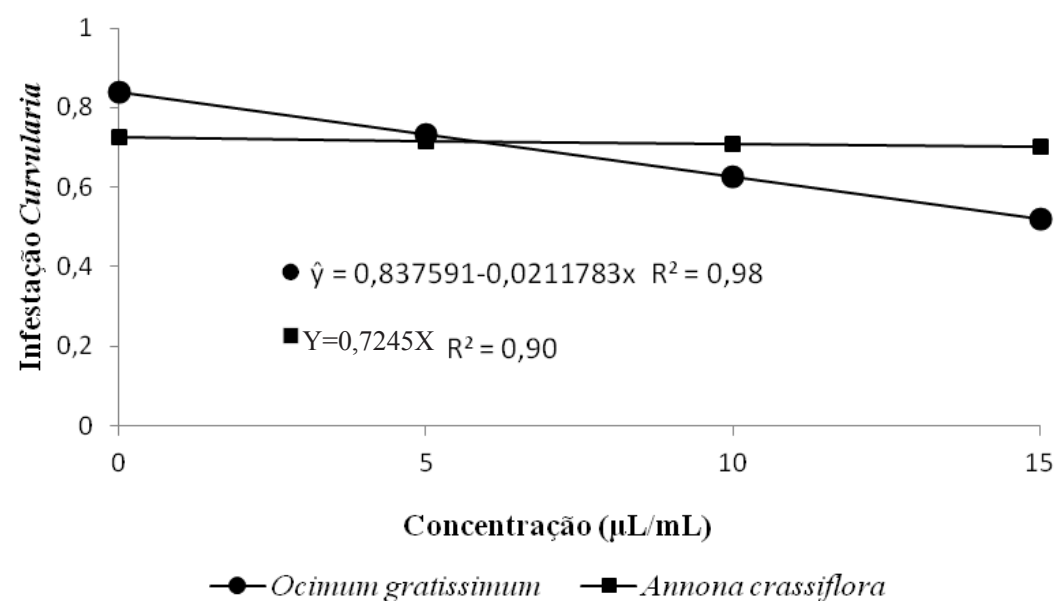

Fonte: Elaboração dos autores.

\section{Qualidade fisiológica das sementes de sorgo}

Nos testes de germinação e vigor, houve interação apenas para os extratos testados, onde o extrato de canela causou redução na primeira contagem de germinação (\%), na germinação (\%) e no índice de velocidade de germinação (IVG) quando comparado ao extrato de hortelã (Tabela 6). O extrato de canela causou redução de $6,1 \%$ na germinação das sementes, $11,7 \%$ na primeira contagem de germinação e 1,8 no IVG em relação ao extrato de hortelã. Viegas et al. (2005) também relataram que o óleo essencial de canela reduziu acentuadamente a germinação de sementes de amendoim e aumentou consideravelmente a porcentagem de plântulas anormais deterioradas. $\mathrm{O}$ extrato de canela possui eugenol que é um fenilpropeno (fenol) pouco solúvel em água que está presente no óleo essencial de certas plantas, dando aroma característico de cravo da índia. Os fenóis são comuns nas plantas 
não sendo tóxicos em quantidade e condições normais (SALUNKHE; CHAVAN; KADAM, 1990), entretanto, em altas concentrações podem vir a ser. Em sorgo, os compostos fenólicos são altamente correlacionados com a germinação. Do ponto de vista bioquímico, o alto conteúdo de compostos fenólicos no tegumento das sementes pode se ligar fortemente ao tanino por meio de pontes de hidrogênio inibindo a germinação. Isso é definido como dormência química (OLIVEIRA et al., 2011). Outros relatos causando redução na qualidade fisiológica em sementes já foram observados. O extrato de aroeira puro reduziu a germinação em sementes de algodão (SOUZA et al., 2003) e o uso de diferentes dosagens do óleo de citronela interferiu negativamente na germinação e no vigor de sementes de Vigna unguiculata.

Tabela 6. Germinação e vigor de sementes de sorgo tratadas com extratos de Cinnamomum zeylanicum e Mentha spicata em relação à testemunha.

\begin{tabular}{cccc}
\hline Extratos & Germinação (\%) & $\begin{array}{c}\text { Primeira contagem } \\
\text { germinação (\%) }\end{array}$ & IVG \\
\hline Cinnamomum zeylanicum & $86,5 \mathrm{~b}$ & $68,4 \mathrm{~b}$ & $20,9 \mathrm{~b}$ \\
Testemunha & 89,5 & 67,0 & 22,2 \\
Mentha spicata & $92,6 \mathrm{a}$ & $80,1 \mathrm{a}$ & $22,7 \mathrm{a}$ \\
Testemunha & 90,5 & 79,0 & 21,8 \\
\hline CV $(\%)$ & 3,96 & 11,99 & 5,36 \\
\hline
\end{tabular}

Médias seguidas pela mesma letra minúscula na coluna, não diferem entre si pelo teste de Tukey a 5\% de probabilidade.

Fonte: Elaboração dos autores.

Piveta et al. (2007) relataram que os extratos de hortelã não influenciaram na germinação das sementes de angico vermelho e, também foi verificado neste estudo que não houve redução da germinação e do vigor nas sementes de sorgo quando se utilizou este extrato se comparado à testemunha. No entanto Bonfim et al. (2011) relataram que o extrato de hortelã em diferentes concentrações $(25 \%, 50 \%, 75 \%$ e $100 \%)$ reduziu a germinação e vigor de sementes de Plantago major. Contudo, estas dosagens foram superiores às utilizadas neste estudo. A hortelã apresenta efeito alelopático sobre a germinação de sementes, provavelmente devido aos monoterpenos presentes nas espécies do gênero Mentha (MAIA et al., 2011). Os monoterpenos, os quais podem causar extensivos danos às membranas e ao processo respiratório das células (GERSHENZON; McCONKEY; CROTEAU, 2000), são componentes majoritários dos óleos essenciais de um grande número de espécies e têm sido relatados como aleloquímicos eficazes pelo efeito tóxico sobre a germinação de sementes (SOUZA FILHO et al., 2009). Com isso, pode ser presumido que os monoterpenos estão em maior concentração nos óleos essenciais, e extratos brutos superiores a $25 \%$, causando toxicidade nas sementes, contudo necessita-se de maiores estudos para esclarecer e afirmar tal hipótese.

Houve interação entre os óleos essenciais e as concentrações testadas, o que influenciou a germinação e o IVG das sementes (Tabelas 7 e 8; Figuras 5 e 6). O óleo essencial de alfavaca cravo proporcionou redução linear da germinação e do índice de velocidade de germinação com o aumento das concentrações conforme as Figuras 5 e 6 . A concentração de $15 \mu \mathrm{L} / \mathrm{mL}$ foi a que apresentou maior efeito tóxico sobre os atributos fisiológicos avaliados. Contudo este efeito tóxico não foi observado no tratamento com óleo de araticum não comprometendo a viabilidade e no vigor das sementes de sorgo. Para Ferreira e Borghetti (2002) o efeito alelopático, muitas vezes, não se dá pela germinabilidade, mas sobre a velocidade de germinação, ou seja, sobre o vigor das sementes. 
Tabela 7. Germinação (\%) de sementes de sorgo tratadas com óleos essenciais de Ocimum gratissimum e Annona crassiflora.

\begin{tabular}{ccc}
\hline Concentração $(\boldsymbol{\mu l} / \mathbf{m L})$ & Ocimum gratissimum & Annona crassiflora \\
\hline 0 & $96,0 \mathrm{a}$ & $93,5 \mathrm{a}$ \\
5 & $95,0 \mathrm{a}$ & $95,0 \mathrm{a}$ \\
10 & $91,5 \mathrm{a}$ & $90,5 \mathrm{a}$ \\
15 & $90,5 \mathrm{~b}$ & $95,5 \mathrm{a}$ \\
\hline $\mathrm{CV}(\%)$ & 2,68 & 3,27 \\
\hline
\end{tabular}

Médias seguidas pela mesma letra minúscula na linha não diferem entre si pelo teste de Tukey a 5\% de probabilidade.

Fonte: Elaboração dos autores.

Tabela 8. Índice de velocidade de germinação de sementes de sorgo tratadas com óleos essenciais de Ocimum gratissimum e de Annona crassiflora.

\begin{tabular}{ccc}
\hline Concentração $(\boldsymbol{\mu l} / \mathbf{m L})$ & Ocimum gratissimum & Annona crassiflora \\
\hline 0 & $23,6 \mathrm{a}$ & $23,3 \mathrm{a}$ \\
5 & $23,1 \mathrm{a}$ & $23,6 \mathrm{a}$ \\
10 & $21,7 \mathrm{a}$ & $22,6 \mathrm{a}$ \\
15 & $20,3 \mathrm{~b}$ & $23,5 \mathrm{a}$ \\
\hline $\mathrm{CV}(\%)$ & 3,47 & 5,65 \\
\hline
\end{tabular}

Médias seguidas pela mesma letra minúscula na linha, não diferem entre si pelo teste de Tukey a 5\% de probabilidade.

Fonte: Elaboração dos autores.

Figura 5. Porcentagem de germinação das sementes de sorgo tratadas com óleos essenciais de $O$. gratissimum e $A$. crassiflora.

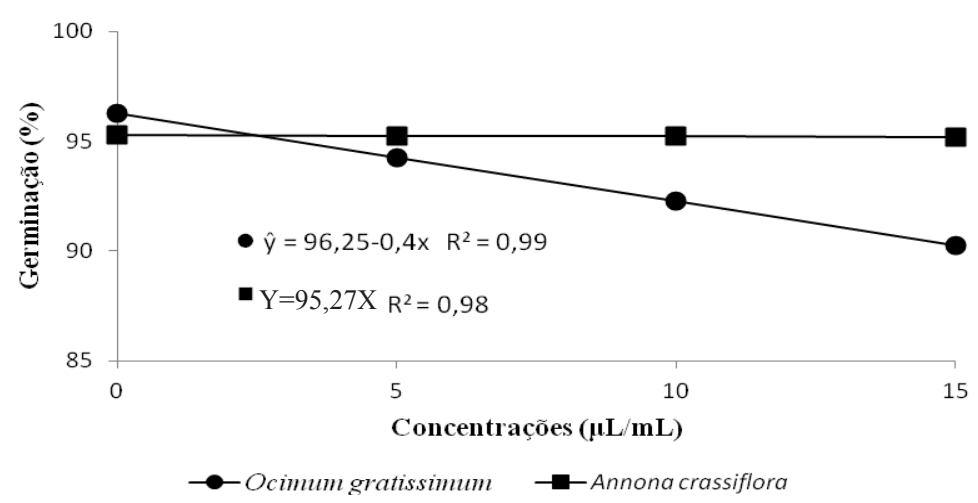

Fonte: Elaboração dos autores.

No óleo essencial extraído de $O$. gratissimum são encontrados os seguintes compostos: 1,8 cineol, eugenol, metil-eugenol, timol, p-cimeno, cisocimeno e cis-cariofileno (BIASI et al., 2009). Como mencionado anteriormente, eugenol, monoterpenos ( 1,8 cineol e cis-ocimeno) e terpenos (timol e ciscariofileno) podem também ter influenciado na redução da germinação nas sementes de sorgo. No entanto, Rodrigues et al. (2006) estudaram o óleo essencial da planta Ocimum gratissimum no tratamento de sementes contra Bipolaris sorokiniana em teste de areia e concluíram que o mesmo não teve influencia na emergência, altura e na massa fresca de plântulas. 
Figura 6. Índice de velocidade de germinação de sementes de sorgo tratadas com óleos essenciais de O. gratissimum.

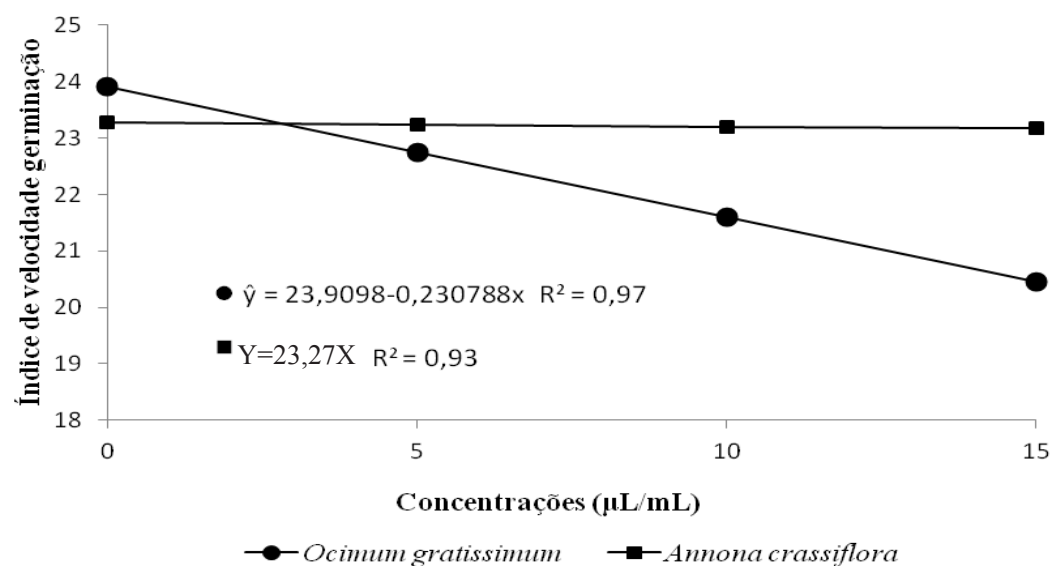

Fonte: Elaboração dos autores.

De modo geral, vários danos podem ser provocados por patógenos, associados às sementes. Uma alternativa para o controle desses patógenos é a utilização de subprodutos de plantas medicinais (extrato bruto, óleo essencial) uma vez que apresentam, em sua composição, substâncias com propriedades fungicidas e/ou fungitóxicas. O tratamento de sementes é uma das etapas mais importantes para manter a qualidade fisiológica e o vigor das sementes e neste sentido há uma busca por formas eficientes e econômicas de se controlar patógenos prejudiciais às sementes.

\section{Conclusão}

O extrato aquoso de canela (Cinnamomum zeylanicum) e o óleo essencial de alfavaca cravo (Ocimum gratissimum) reduzem a infestação dos fungos, principalmente de Curvularia, porém apresentam efeito fitotóxico reduzindo a viabilidade e o vigor das sementes de sorgo.

\section{Referências}

ARAÚJO, R. C. Z.; CHALFOUM, S. M.; ANGÉLICO, C. L.; ARAUJO, J. B. S.; PEREIRA, M. C. Avaliação in vitro da atividade fungitóxica de extratos de condimentos na inibição de fungos isolados de pães artesanais. Ciência e Agrotecnologia, Lavras, v. 33, n. 2, p. 545-551, 2009.
BIASI, L. A.; MACHADO, E. M.; KOWALSKI, A. P. J.; SIGNOR, D.; ALVES, M. A.; LIMA, F. I.; DESCHAMPS, C.; CÔCCO, L. C.; SHEER, A. P. Adubação orgânica na produção, rendimento e composição do óleo essencial da alfavaca quimiotipo eugenol. Horticultura Brasileira, Brasília, v. 27, n. 1, p. 35-39, 2009.

BONFIM, F. P. G.; HONÓRIO, I. C. G.; CASALI, V. W. D.; FONSECA, M. C. M; MANTOVANIALVARENGA, E.; ANDRADE, F. M. C. PEREIRA, A. J.; GONÇALVES, M. G. Potencial alelopático de extratos aquosos de Melissa officinalis L. e Mentha x villosa L. na germinação e vigor de sementes de Plantago major $L$. Revista Brasileira de Plantas Medicinais, Botucatu, v. 13, p. 564-568, 2011. Número Especial.

BRASIL. Ministério da Agricultura, Pecuária e Abastecimento. Regras para analise de sementes. Ministério da Agricultura, Pecuária e Abastecimento. Secretaria de Defesa Agropecuária. Brasília: MAPA/ ACS, 2009. $395 \mathrm{p}$.

BRITO, N. M.; NASCIMENTO, L. C.; COELHO, M. S. E.; FÉLIX, L. P. Efeitos de óleos essenciais na germinação de sementes de Cereus jamacaru. Revista Brasileira de Ciências Agrárias, Recife, v. 5, n. 2, p. 207-211, 2010.

CARVALHO, L. F.; MEDEIROS FILHO, S.; ROSSETTI, A. G.; TEÓFILO, E. M. Condicionamento osmótico em sementes de sorgo. Revista Brasileira de Sementes, Londrina, v. 22, n. 1, p.185-192, 2000.

CECCHI, H. M. Fundamentos teóricos e práticos em análise de alimentos. 2. ed. Campinas: Unicamp, 2003. $207 \mathrm{p}$. 
COELHO, M. F. B.; MAIA, S. S. S.; OLIVEIRA, A. K.; DIÓGENES, F. E. P. Atividade alelopática de extrato de sementes de juazeiro. Horticultura Brasileira, Brasília, v. 29, n. 1, p. 108-111, 2011.

FOOD AND AGRICULTURE ORGANIZATION OF THE UNITED NATIONS - FAO. Coarse grains. 2012. Disponível em: <http://www.fao.org/docrep/010/ai466e/ ai466e 04.htm>. Acesso em: 09 set. 2013.

FERREIRA, A. G.; BORGHETTI, F. Germinação: do básico ao aplicado. Porto Alegre: Editora Artmed, 2002. $324 \mathrm{p}$.

GARCIA, R. A.; JULIATTI, F. C.; BARBOSA, K. A. G.; CASSEMIRO, T. A. Atividade antifúngica de óleo e extratos vegetais sobre Sclerotinia sclerotiorum. Bioscience Journal, Uberlândia, v. 28, n. 1, p. 48-57, 2012.

GERSHENZON, J.; McCONKEY, M. E.; CROTEAU, R. B. Regulation of monoterpene accumulation in leaves of peppermint. Plant Physiology, United Kingdom, v. 122, n. 1, p. 205-214, 2000.

HENNING, A. A. Patologia e tratamento de sementes: noções gerais. Londrina: Embrapa, 2005. 52 p.

HILLEN, T.; SCHWAN-ESTRADA, K. R. F.; MESQUINI, R. M.; CRUZ, M. E. S.; STANGARLIN, J. R.; NOZAKI, M. Atividade antimicrobiana de óleos essenciais no controle de alguns fitopatógenos fúngicos in vitro e no tratamento de sementes. Revista Brasileira de Plantas Medicinais, Botucatu, v. 14, n. 3, p.439-445, 2012.

JHAM, G. N.; DHINGRA, O. D.; JARDIM, C. M.; VALENTE, V. M. Identification of the major fungitoxic component of cinnamon bark oil. Fitopatologia Brasileira, Brasília, v. 30, n. 4, p. 404-408, 2005.

MACHADO, J. C. Tratamento de sementes no controle de doenças. Lavras, MG: UFLA, 2000. 138 p.

MAGUIRE, J. D. Speed of germination-aid and evaluation for seedling emergence and vigor. Crop Science, Madison, v. 2, n. 1, p. 176-177, 1962.

MAIA, J. T.L. S.; BONFIM, F. P. G.; BARBOSA, C. K. R.; GUILHERME, D. O.; HONÓRIO, I. C. G.; MARTINS, E. R. Influência alelopática de hortelã (Mentha x villosa Huds.) sobre emergência de plântulas de alface (Lactuca sativa L.). Revista Brasileira de Plantas Medicinais, Paulínia, v. 13, n. 3, p. 253-257, 2011.

MARTINS NETTO, D. A.; PINTO, N. F. J. A.; OLIVEIRA, A. C.; BORBA, C. S.; ANDRADE, R. V. Qualidade Fisiológica e sanitária de sementes de sorgo danificadas. Revista Brasileira de Sementes, Londrina, v. 20, n. 2, p. 134-140, 1998.
OLIVEIRA, J. A.; SILVA, T. T. A.; VON PINHO, E. V. R.; ABREU, L. A. S. Secagem e armazenamento de sementes de sorgo com alto e baixo teor de tanino. Revista Brasileira de Sementes, Londrina, v. 33, n. 4 p. 699-710, 2011.

PINTO, N. F. J. A. Avaliação da eficiência dos fungicidas fludioxonil + metalaxyl-m no tratamento de sementes de sorgo. Ciência e Agrotecnologia, Lavras, v. 28, n. 2, p. 450-453, 2004.

PINTO, N. F. J. A. Tratamento químico de grãos de sorgo úmidos visando o controle de fungos de armazenamento. Revista Brasileira de Armazenamento, Viçosa, v. 26, n. 2, p. 55-59, 2001.

PITT, J. I.; HOCKING, A. D. Fungi and food spoilage. Sydney: Academic Press, 1985.

PIVETA, G.; MIETH, A. T.; PACHECO, C.; HAMANN, F. A.; RODRIGUES, J.; MUNIZ, M. F. B.; BLUNE, E. Qualidade sanitária e fisiológica de sementes de angico vermelho após aplicação de extratos vegetais. Revista Brasileira de Agroecologia, Cruz Alta, v. 2, n. 2, p. 1437 1440, 2007.

PRINS, C. L.; LEMOS, C. S. L.; FREITAS, S. P. Efeito do tempo de extração sobre a composição e rendimento do óleo essencial de Alecrim (Rosmarinus officinalis). Revista Brasileira de Plantas Medicinas, Paulínia, v. 8, n. 4, p. 92-95, 2006.

RABELO, M.; SOUZA, E. P.; SOARES, P. M. G.; MIRANDA, A. V.; MATOS, F. J. A.; CRIDDLE, D. N. Antinociceptive properties of the essential oil of Ocimum gratissimum L. (Labiatae) in mice. Brazilian Journal of Medical and Biological Research, Riberão Preto, v. 36, n. 4, p. 521-524, 2003.

REVERBERI, M.; RICELLI, A.; ZLALIC, S.; FABBRI, A. A.; FANELLI, C. Natural functions of mycotoxins and control of their biosynthesis in fungi. Applied Microbiology and Biotechnology, New York, v. 87, n. 3, p. 899-911, jul. 2010.

RIBAS, P. M. Sorgo: introdução e importância econômica. Sete Lagoas, MG: Embrapa, 2003. 16 p.

RODRIGUES, É. A.; SCHWAN-ESTRADA, K. R. F.; STANGARLIN, J. R.; SCAPIM, C. A.; FIORI-TUTIDA, A. C. G. Potencial da planta medicinal Ocimum gratissimum no controle de Bipolaris sorokiniana em sementes de trigo. Acta Scientiarum Agronomy, Maringá, v. 28 , n. 2 , p. $213-220,2006$.

SALUNKHE, D. K.; CHAVAN, J. K.; KADAM, S. S. Dietary tannins: consequences and remedies. Boca Raton: CRC Press, 1990. 200 p. 
SANTOS, E. S.; CARVALHO, R. A.; LACERDA, J. T. Alternativas naturais e ecológicas no controle de doenças fúngicas do inhame (Dioscorea spp). Tecnologia \& Ciência Agropecuária, João Pessoa, v. 2, n. 2, p. 1-6. 2008.

SILVA, J. A.; PEGADO, C. M. A.; RIBEIRO, V. V.; BRITO, N. M.; NASCIMENTO, L. C. Efeito de extratos vegetais no controle de Fusarium oxysporum f. sp tracheiphilum em sementes de caupi. Ciência e Agrotecnologia, Lavras, v. 33, n. 2, p. 611-616, 2009.

SILVA, J. L.; TEIXEIRA, R. N. V.; SANTOS, D. I. P.; PESSOA, J. O. Atividade antifúngica de extratos vegetais sobre o crescimento in vitro de fitopatógenos. Revista Verde de Agroecologia e Desenvolvimento Sustentável, Mossoró, v. 7, n. 1, p. 80-86, 2012.

SILVA, M. B.; NICOLI, A.; COSTA, A. S. V.; BRASILEIRO, B. G.; JAMAL, C. M.; SILVA, C. A.; PAULA JÚNIOR, T. J.; TEIXEIRA, H. Ação antimicrobiana de extratos de plantas medicinais sobre espécies fitopatogênicas de fungos do gênero Colletotrichum. Revista Brasileira de Plantas Medicinais, Paulínia, v. 10, n. 3, p. 57-60, 2008.

SIQUI, A. C.; SAMPAIO, A. L. F.; SOUZA, M. C.; HENRIQUES, M. G. M. O.; RAMOS, M. F. S. Óleos essenciais - potencial anti-inflamatório. Biotecnologia, Ciência e Desenvolvimento. v. 16, p. 38-43, 2000.

SOUSA, R. M. S; SERRA, I. M. R. S; MELO, T. A. Efeito de óleos essenciais como alternativa no controle de Colletotrichum gloeosporioides, em pimenta. Summa Phytopathologica, Botucatu, v. 38, n. 1, p. 42-47, 2012.

SOUZA FILHO, A. P. S.; VASCONCELOS, M. A. M.; ZOGHBI, M. G. B.; CUNHA, R. L. Efeitos potencialmente alelopáticos dos óleos essenciais de Piper hispidinervium C. DC. e Pogostemon heyneanus Benth sobre plantas daninhas. Acta Amazonica, Manaus, v. 39, n. 2, p. 389-395, 2009.
SOUZA JUNIOR, I. T. S.; SALES, N. L. P.; MARTINS, E. R. Efeito fungitóxico de óleos essenciais sobre Colletotrichum gloeosporioides, isolado do maracujazeiro amarelo. Revista Biotemas, Florianópolis, v. 22 , n. 3, p. 77-83, 2009.

SOUZA,A.A.; BRUNO, R. L.A.;ARAÚJO, E.; BRUNO, G. B. Micoflora e qualidade fisiológica de sementes do algodoeiro tratadas com fungicidas químicos e extrato de aroeira. Revista Brasileira de Sementes, Londrina, v. 25, n. 1, p. 56-64, 2003.

SOUZA, A. E. F.; ARAÚJO, E.; NASCIMENTO, L. C. Atividade antifúngica de extratos de alho e capim-santo sobre o desenvolvimento de Fusarium proliferatum isolado de grãos de milho. Fitopatologia Brasileira, Brasília v. 32, n. 6, p. 465-471. 2007.

VENTUROSO, L. R.; BACCHI, L. M. A.; GAVASSONI, W. L.; CONUS, L. A.; PONTIM, B. C. A.; BERGAMIN, A. C. Atividade antifúngica de extratos vegetais sobre o desenvolvimento de fitopatógenos. Summa Phytopathologica, Botucatu, v. 37, n. 1, p. 18-23, 2011.

VIEGAS, E. C.; SOARES, A.; CARMO, M. G. F.; ROSSETTO, C. A. V. Toxicidade de óleos essenciais de alho e casca de canela contra fungos do grupo Aspergillus flavus. Horticultura Brasileira, Brasília, v. 23, n. 4, p. 915-919, 2005.

VIEIRA, R. F.; SIMON, J. E. Chemical characterization of basil (Ocimum spp.) found in the markets and used in traditional medicine in Brazil. Economic Botany, Coverage, v. 54, n. 2, p. 207-16, 2000. 